\title{
Development of a vaginal preparation providing both prophylaxis against venereal disease and contraception
}

\author{
J. C. CUTLER, B. SINGH, AND H. M. D. UTIDJIAN \\ Graduate School of Public Health, University of Pittsburgh, Pittsburgh, Pennsylvania, \\ AND \\ R. C. ARNOLD \\ Missouri Crippled Childrens Service, Columbia, Missouri, U.S.A.
}

In view of the growing public health concern with the increasing rates of venereal infections and of unplanned pregnancies, and in view of the public policy expressed by both WHO and many governments calling for integration of family-planning programmes into other public health efforts, it seems appropriate to investigate means of simultaneous protection against both venereal disease and pregnancy.

The dual role of the condom in this respect has been known for many generations, although in certain parts of the United States the condom is now considered by men to be contraceptive rather than prophylactic.

The possible role of vaginal contraceptive preparations in providing secondary protection against venereal infection was described once again at the 26th General Assembly (IUVDT, 1969).

With the world-wide rise in venereal disease rates in spite of the existence of specific therapeutic agents and with the difficulties faced by most countries in attempting to meet the problem because of budgetary, manpower, and clinical shortages, it seems desirable to reintroduce the concept of prophylaxis as an element of the venereal disease control programme, and to involve patients and potential patients in the control efforts.

In theory, a campaign to encourage the use of the condom, or of vaginal contraceptives if found to be prophylactic, as parts of venereal diease control programmes should help to reduce unplanned pregnancies as well as venereal infections.

Conversely, particularly in view of the relatively high rate of gonorrhoeal infection encountered in certain U.S.A. family-planning clinics with a high percentage of unmarried females among the clientèle, increased use of the condom, or vaginal contracepThis work was carried out under the Contract No. AID csd/2822 tive agents if found to be prophylactic, should assist in reducing the female reservoir of gonorrhoea.

Of particular significance from the public health point of view, in the prevention of both venereal disease and of unplanned pregnancy, is the fact that neither condom nor any of the vaginal contraceptives-creams, jellies, suppositories, foams, or foaming tablets-require a prescription or the involvement of a physician. As had been amply demonstrated in wartime experience, good health-education coupled with availability of the agents can promote effective prophylactic practice with the added potential benefit of reducing unplanned pregnancies.

It is necessary to pay particular attention in dealing with both venereal disease and unplanned pregnancy to the unmarried, sexually active group under the age of 25 years. Their pattern of sexual behaviour, as demonstrated by venereal disease epidemiological studies, places them at high risk in both respects. Furthermore, it is this same age group that does not have access to, or the habit of utilizing, the physicians' services.

The success of the family-planning programme of the Government of India in promoting the use of the condom may well serve as a model for its widespread adoption for both contraception and prophylaxis. If any vaginal preparations are found to be of prophylactic value, the possibilities for building on the Indian experience are obvious.

For these reasons, a study was begun in 1970 under contract from the U.S. Agency for International Development to determine the effectiveness in vitro of the vaginal contraceptive agents currently marketed in the U.S.A. as possible prophylactic agents against $T$. pallidum, $N$. gonorrhoeae, $T$. vaginalis, C. albicans, and other vaginal pathogens.

All the vaginal preparations currently accepted for sale in the U.S.A. have been tested in vitro by 
standard procedures against the gonococcus and the treponeme (Singh, Cutler, and Utidjian, 1972). Those showing most promise have been tested in the rabbit for prophylactic efficacy against $T$. pallidum using standard methods (Arnold and Cutler, 1956).

Several contraceptive agents have been found to be active in vitro against the organisms listed above. Within the next month, now that FDA approval has been given, field trials with certain selected vaginal contraceptives will start in the local venereal disease clinic patients. Those female patients, who are evidently at higher risk in that they have already been treated at least once for gonorrhoea in the past year, will be used for the investigation.

The present experimental design proposes to treat a series of 150 patients. Fifty will be controls and two groups of fifty will be given one or other of the first two preparations approved for clinicalt rial. The study period for each subject is to be one year, so that the entire study will require about $2 \frac{1}{4}$ years.

It is hoped to be able to provide a progress report for the first year at the next meeting of the IUVDT.

\section{References}

ARNold, R. C., and Cutler, J. C. (1956) Brit. f. vener. Dis., 32,34

IUVDT (1969) Med. Offr, 122, 45 (Report on the 26th General Assembly)

Singh, B., CUTLER, J. C., and Utidjian, H. M. D. (1972) Brit. F. vener. Dis., 48, 57 